\title{
Split Torque Transmission Load Sharing
}

T.L. Krantz

Propulsion Directorate

U.S. Army Aviation Systems Command

Lewis Research Center

Cleveland, Ohio

M. Rashidi

Cleveland State University

Cleveland, Ohio

and

J.G. Kish

Sikorsky Aircraft

Stratford, Connecticut

Prepared for the

"Gearbox Configurations of the 90's"

sponsored by the Institute of Mechanical Engineers

Solihull, West Midlands, United Kingdom, October 28, 1992 


\title{
SPLIT TORQUE TRANSMISSION LOAD SHARING
}

\author{
T.L. Krantz \\ Propulsion Directorate \\ U.S. Army Aviation Systems Command \\ Lewis Research Center \\ Cleveland, Ohio 44135 \\ M. Rashidi \\ Cleveland State University \\ Cleveland, Ohio 44115 \\ J.G. Kish \\ Sikorsky Aircraft \\ Division of United Technologies Corp. \\ Stratford, Connecticut 06601
}

\section{SUMMARY}

Split torque transmissions are attractive alternatives to conventional planetary designs for helicopter transmissions. The split torque designs can offer lighter weight and fewer parts but have not been used extensively for lack of experience, especially with obtaining proper load sharing. Two split torque designs that use different load sharing methods have been studied. Precise indexing and alignment of the geartrain to produce acceptable load sharing has been demonstrated. An elastomeric torque splitter that has large torsional compliance and damping produces even better load sharing while reducing dynamic transmission error and noise. However, the elastomeric torque splitter as now configured is not capable over the full range of operating conditions of a fielded system. A thrust balancing load sharing device was evaluated. Friction forces that oppose the motion of the balance mechanism are significant. A static analysis suggests to increase the helix angle of the input pinion of the thrust balancing design. Also, dynamic analysis of this design predicts good load sharing and a significant torsional response to accumulative pitch errors of the gears.

\section{INTRODUCTION}

A rotorcraft's performance is greatly influenced by the performance of its drive system. The next generation of rotorcraft will require drive systems that are lighter, quieter, and more reliable than the state of the art. These improvements are needed to increase the vehicle's payload and performance, improve passenger comfort and safety, lower operating costs, and improve readiness. One of the most important characteristics of the drive system is the geartrain arrangement. The most common final gear stage for a helicopter main rotor transmission is a planetary stage which features an output shaft driven by several planets. An advantage of the planetary stage compared to a simple parallel shaft arrangement is that each planet gear must transmit only a part of the total torque. This load sharing results in a smaller, lighter transmission. An alternative to a planetary stage which also transfers power to the output shaft through multiple power paths is a split torque stage. White (ref. 1) has advocated the use of split torque geartrains for helicopters, stating that these designs offer the following advantages over conventional arrangements: 
(1) High ratio of speed reduction at the final stage

(2) Reduced number of reduction stages

(3) Lower energy losses

(4) Increased reliability of the separate drive paths

(5) Fewer gears and bearings

(6) Lower noise.

Planetary stages for helicopters have been used, studied, and developed extensively, but split torque stages have seen little use. A concern for designers of either configuration has been to ensure that the power is split evenly among the parallel power paths. Several methods to achieve an equal power split with split torque designs have been proposed (refs. 1 to 5 ). The relative merits of these and other load sharing methods have yet to be rigorously established. In this work, two load sharing methods have been studied. One relies on balancing of thrust loads while the second relies on the torsional compliance of the load paths to achieve good load sharing. This article presents the methods and results of the study of these load sharing methods.

\section{SPLIT TORQUE CONCEPTS}

In this article, a split torque geartrain refers to any parallel shaft gear arrangement like the configuration shown in figure 1. This type of arrangement is also sometimes called a split path design. A helicopter split torque main rotor drive system could consist of a bevel gear reduction with such a split torque stage. The split torque stage has two speed reduction stages. The pinion of the first stage engages with two gears. The power is split between these two gears and carried by two second stage pinions. The two pinions drive the second stage gear which is referred to as the bull gear. The design is similar to a planetary stage in that the torque is shared among multiple paths. However, the final gear stage of the split torque design can have a larger reduction ratio than is possible for a planetary stage. A larger reduction ratio at the final stage tends to reduce the weight of the gearbox. This feature of the split torque geartrain makes it an attractive option, especially for helicopters where minimal weight is desired.

For either a planetary or split torque design, the torque carried by each of the multiple paths should be as near as to equal as possible at any time. This concept is often termed load sharing. Methods have been studied and developed to achieve good load sharing in planetary systems. These methods include floating sun gears, flexible mounted ring gears, planet gear phasing, and planet gear indexing. Also, typically, the planet gear supports are located very accurately and gear dimensions are held to tight tolerances to ensure good load sharing. In general, planetary stages of helicopters are considered to have good load sharing, and they have been used very successfully.

Load sharing is also an important consideration for split torque designs. The load sharing issue is a result of deviations of the gearbox from ideal geometry and properties. A split torque arrangement creates a locked geartrain, as represented by the heavy line in figure 1, with four gear meshes about the locked loop. If all geometry is ideal, then all four gear meshes will be in contact under a small nominal torque. In practice, the geometry will not be ideal, and three meshes will be in contact while the fourth mesh location will have some backlash. As more torque is applied to the system, deformation will occur in the loaded path until the backlash at the fourth mesh location is eliminated. Since torque was absorbed to eliminate the backlash, the load sharing will not be equal. The load sharing for this design will also be affected if the 
stiffnesses of the two load paths are not matched. Split torque load sharing methods aim to either; (1) accommodate deviations from ideal geometry to eliminate the no load backlash, or (2) minimize the torque required to bring the mesh with backlash into contact.

One proposed method for split torque load sharing makes use of an epicyclic gear stage (fig. 2). The epicyclic stage has one input member and two output members of equal power. Any deviations from ideal geometry that could result in unequal load sharing is accommodated by a small relative rotation of the sun and ring gears. The geartrain of figure 2 has another degree of freedom compared to that of figure 1. This added degree of freedom guarantees equal load sharing but adds weight and complexity to the system.

A second proposed method for split torque load sharing makes use of helical gears. Backlash within the locked loop geartrain can be eliminated by adjusting the axial positions of helical gears. The axial positions can be adjusted by custom shimming each gearbox at assembly or by a self adjusting mechanism that moves the helical gears axially in response to thrust loads induced by torque. Figure 3 is one such self adjusting design.

A third proposed method for split torque load sharing makes use of the compliance between the splitting mesh gears and the combining mesh pinions. The larger the compliance, the smaller the torque that will be required to bring a given amount of backlash into contact. Of course, this compliant member must also be strong enough to carry the required torque at full power. Also to be considered, the better the precision of the components of the gearbox, the smaller the backlash that will be present under no load. For this method, there is a trade off between the compliance required to accommodate backlash and the precision required. The more compliant the load paths, the less precision that is required.

\section{SIKORSKY AIRCRAFT SPLIT PATH TRANSMISSION}

\section{Description of Design}

A helicopter drive system that includes a split path concept has been designed and researched by Sikorsky Aircraft Company for the U.S. Army's Advanced Rotorcraft Transmission (ART) program. The drive system was designed to meet the requirements of an Advanced Cargo Aircraft heavy lift vehicle with a projected $36000-\mathrm{kg}$ ( $80000-\mathrm{lb})$ gross weight, $11000-\mathrm{kg}$ (25 000-lb) payload, and 500-km (310-mile) mission radius. The goals of the ART program were to enable the technologies needed for a $10 \mathrm{~dB}$ noise reduction and 25 percent weight reduction compared to a state-of-the-art transmission while obtaining a 5000-hr mean time between removal reliability. Sikorsky Aircraft projected that the vehicle would be powered by three engines, have a $33.4-\mathrm{m}(110-\mathrm{ft})$ diameter main rotor and require a main gearbox rated for a limit of $23860 \mathrm{~kW}(32000 \mathrm{hp})$.

A split path design was selected as the best configuration for the Advanced Cargo Aircraft. This design relies on the compliance of the load paths to obtain good load sharing. The main transmission is illustrated in figure 4. The transmission has three stages of gearing. The first stage is a spiral bevel gear set. The second stage is a high contact ratio spur mesh with the power splitting to dual paths. The third and final stage is an 11:1 reduction ratio double helical mesh where the power is recombined. The weight of this split path design is significantly influenced by the reduction ratio of the final gear stage as illustrated in figure 5 . For this design, the reduction ratio is limited by the strength of the double helical pinion shafts 
in bending. For the selected 11:1 final stage reduction ratio, the output bull gear has a 1.22-m (48-in.) pitch diameter. The drive system with this transmission was evaluated to be 23 percent lighter and to generate $10 \mathrm{~dB}$ less noise than a state-of-the-art design while having a $3890-\mathrm{hr}$ mean time between removal. These drive system performance improvements are a result of the split path configuration and the following component technologies:

(1) Composite gearbox housing

(2) Composite drive shafts

(3) High speed spring clutch

(4) High hot hardness steel

(5) Angular contact spherical roller bearings

(6) High reduction ratio gear mesh at the output stage

(7) Wide face width, high contact ratio double helical mesh

(8) Topologically ground tooth profiles

(9) Split path load sharing methods.

Items 4 to 9 were selected for study, development, and demonstration in the ART program. The results of the program have been documented (refs. 6 to 8 ). The methods and results of the research of split path load sharing methods are presented and discussed here.

\section{EXPERIMENTAL METHOD}

A one-half scale gearbox and test facility were built and tests were conducted to study the new technologies including split path load sharing. The one-half scale gearbox, shown in figure 6, duplicates the final two stages of the split path gearbox for one engine path but at one half geometric scale. One half scale was chosen to reduce fabrication costs of the hardware and test facility. By using the same speed as the full scale gearbox, reducing the power to one eighth, and scaling the components by one half, the tested components experience the same bending stresses, Hertz stresses, and deflections as the full scale design. Also, component life and reliability are the same notwithstanding material allowables based on size effects. However, the sliding velocities of the one-half scale gear meshes are half of the full scale components. To study the load sharing, the torques in each of the dual paths, transmission errors, and acoustic noise were measured and analyzed.

The load sharing concept proposed and tested in the ART project makes use of the torsional compliance between the splitting mesh gears and the combining mesh pinions. Two designs using this concept were tested, one with a large torsional compliance and one with a large torsional stiffness. A compliant device was developed and tested to determine the capabilities of the device and to study the resulting dynamics and performance of the gearbox. The gearbox was also tested with a stiff shaft installed in place of the compliant device. When using the stiff shaft, the torque splitting gear and combining pinion were precisely indexed to each other while also maintaining precise tolerances for machining and assembly of the rest of the gearbox. By testing both designs, the relationship between the precision of the assembly and the torsional compliance required for the load path was quantified. Also, the dynamics and performance of the gearbox with the torsionally stiff shaft was compared to that of the gearbox with the compliant device. 
The device used to provide torsional compliance between the torque splitting gear and combining pinion, an elastomeric load sharing device, is shown in figure 7. Alternate thin layers of nitrile rubber and steel are stiff in the direction perpendicular to the laminates but allow large deflections in the parallel direction. The laminates are located at an angle to the axis of rotation on two halves that are bolted together. The laminates are compressed and a preload force created as the two halves are drawn together during assembly. The magnitude of the compressive preload force is important because it controls the magnitude of the friction force between the spur gear hub and isolator halves. The torque on the gear is transmitted by the frictional forces between these surfaces. Larger preloads create a larger torque capacity, but if the preload is too large the material will yield and fail. The elastomeric torsional isolator shown is about five times more compliant in torsion than an all steel assembly of the same dimensions. The all steel versions were assembled carefully to properly index the two gears on the common shaft.

\section{EXPERIMENTAL RESULTS}

Some typical experimental data is presented in figure 8 . The torque carried in each of the dual paths was measured and is plotted against the total combined torque. The data shown is for testing with the compliant elastomeric torque splitting devices installed, but the trends shown on the plot are also typical for testing with the stiff shaft installed.

If the torque split was ideal, all of the data of figure 8 would fall on the ideal line. However, the slopes of the data do not match the slope of the ideal line. This indicates that the total torsional stiffnesses of the dual power paths are not equal. In the case shown, the stiffness of path number 2 is greater than path number 1 . It is by chance that as the total combined torque increases the torque split approaches the ideal case. It is equally likely that the slopes of the experimental data could diverge as the total combined torque increased. This mismatching of the stiffnesses of the dual paths is one possible source of an unacceptable torque split. A second way that the experimental data does not match the ideal case is that path number 2 carries zero torque until the total combined torque is approximately $450 \mathrm{n}-\mathrm{m}$ (330 ft-lb). As the combined torque was increased from 0 to $450 \mathrm{n}-\mathrm{m}$, path number 1 absorbed all of the torque while a backlash condition existed in path number 2. At $450 \mathrm{n}-\mathrm{m}$ of torque, enough deflections had occurred to eliminate the backlash, and both power paths began to share the total torque. The amount of torque required to absorb the backlash must be properly controlled to ensure an acceptable torque split.

Both designs tested proved to be feasible. The mean torque carried by the dual paths was equal within 5 percent for both designs. The relationship between the torsional compliance of the dual paths and the precision required in assembly was quantified by the experiments. It was demonstrated that precise indexing, tolerances, and assembly of a gearbox can be used with a torsionally stiff shaft to produce an acceptable torque split. Although both designs were feasible, the behavior observed during the two tests was different.

The transmission error measured at the helical pinion for each of the two tests at identical operating conditions is shown in figure 9. One significant difference is that the magnitude of the maximum peak-to-peak transmission error is more than 50 percent less when using the elastomeric isolator. Also, the speed at which the maximum transmission error occurred is different. One would expect that the large compliance of the isolator would shift the resonance condition to a lower frequency. The maximum response, however, occurred at a higher speed with the 
elastomeric isolator compared to the steel assembly. It is likely that the two peak responses are two different mode shapes being excited within the speed range shown. Also significant is that the transmission errors measured when operating away from a resonance condition were smaller while testing with the elastomeric isolator installed. This suggests that the isolator may be effective in reducing dynamic tooth loads.

Another observed difference in behavior was that the audible noise produced while testing the elastomeric isolator was significantly less compared to that while testing the all steel assemblies. This is consistent with the lower transmission errors and lower vibrations that were measured with the elastomeric isolators installed. The elastomers provide a high degree of damping not normally found in helicopter transmission components. More research and study is needed to state conclusively whether the reduction in transmission error and noise was the result of added compliance, added damping, or both.

The transmission error measurements and observed noise difference makes the torsional isolator an attractive option. The isolator also would have the advantage of relaxing costly, precise manufacturing tolerances. However, an unexpected and undesirable characteristic of the present design was discovered during endurance testing. The torque split between the two power paths changed slightly during the testing. It was later verified that the spur gear and isolator halves that make up the isolator assembly had slipped with respect to one another, which affected the torque split. The slippage was a result of nitrile rubber and steel having different thermal expansion rates. For the isolator geometry used, as the temperature of the assembly increased, the load in the laminated area increased. A test was conducted where a nitrile rubber laminate was compressed by a predetermined amount and held at that dimension. The test specimen was subjected to temperature cycles while being held at a constant compressed dimension, and the compressive load in the laminate was measured. Figure 10 is a plot of the test results. Note that during the first cycle over a time scale of $600 \mathrm{~min}$, with the temperature held at a constant $121{ }^{\circ} \mathrm{C}$ and the deflection held constant, the compressive load decreased by about 30 percent. Using the results of these tests, the effect of the temperature cycles experienced by the elastomeric torque splitter during testing in the one-half scale gearbox was calculated. It was found that under repeated heating and cooling, the preload had decreased significantly enough to reduce the torque capacity below the design torque, and slippage occurred during testing. Furthermore, the assembled preload at room temperature could not be adjusted to compensate for the desired operating temperature range without either reaching a yield stress at the highest temperature or losing needed torque capacity at the lowest temperature. The elastomeric torque splitter, in its current configuration, does not have the needed torque capacity over the entire range of temperatures required for a fielded system. However, an alternate robust design using another elastomer material, a temperature compensating arrangement, or an alternate structure and material for the shaft and hub may be possible.

\section{NASA LEWIS SPLIT TORQUE GEARBOX}

\section{Description of Design}

A helicopter drive system that includes a split torque concept has been developed and studied cooperatively by the U.S. Army and NASA Lewis Research Center. This gearbox arrangement was proposed and developed by G. White (ref. 2) under an Army/NASA contract to approximate the power requirement and match the speed reduction requirement of a version of the U.S Army's OH-58 helicopter main rotor transmission. The final two gear stages of the 
split torque design is shown in figure 3. This design relies on positioning of helical gears by a self adjusting mechanism to obtain good load sharing. A main rotor transmission using this concept was projected to be 25 percent lighter than a conventional design using a planetary output stage.

A split torque test gearbox using this design has been built and is being studied. The test gearbox has been built for research of split torque concepts and is not being proposed as an optimal solution for helicopter drive systems. The rated input power to the test gearbox is $373 \mathrm{~kW}(500 \mathrm{hp})$ at $8780 \mathrm{rpm}$. The input power is carried through the input helical pinion and split between two helical gears at the first reduction stage. The power is combined at the second and final reduction stage. Two spur pinions drive the output bull gear at $347.5 \mathrm{rpm}$. Thrust loads are produced at each of the two helical meshes. These thrusts, which are proportional to the torques carried by the gears, are reacted through a pivoted balance beam. The balance beam acts to balance the thrust loads by coupling together the axial positions of the two helical gear/spur pinion assemblies, which are labeled as compound shafts in figure 3 . If the thrust loads are balanced, the power is split evenly between the two parallel paths. This design has been studied analytically to evaluate the load sharing mechanism and the gearbox's characteristics.

\section{Analytical Evaluation}

The NASA Lewis split torque test gearbox has been studied analytically to determine the loads and motions of the gearbox. Both static and dynamic analysis were completed. The results of the static loads analysis are summarized in table I. Note that although the gearbox has a symmetric geometry, the static loads of the two power paths are not the same. Also, the direction of the radial force on a bearing is not in the direction of the line of action of the gear mesh, as is the case for a pinion shaft that engages only one gear. This may significantly change the coupling of the lateral and torsional vibration modes for that shaft through the bearings. For example, table II shows the result of a calculation of a coupled bearing stiffnesses for bearing number 7 of table I. Note that in the case of the gear mesh line of action being coincident with the bearing force, the cross coupling terms are positive and fairly significant. However, for the proposed design, the line of action and bearing force have different directions, and the cross coupling, terms when defined in the direction of the line of action are negative. Since the loads and stiffnesses of the two power paths are different, one should expect that the motions and vibrations of the two paths could be significantly different.

The balance beam mechanism was evaluated using a static analysis. If one ignores friction forces, then for the static condition the torque splits exactly between the two power paths. However, there are friction forces at the bearing supports and contacting gear teeth that resist the motion of the balancing beam. An analysis was done for an assumed coefficient of friction $=0.005$, a typical number for elastohydrodynamic lubrication (ref. 9). The torque split condition that would create a sufficient difference in thrust forces to overcome friction was calculated for varying helix angles and constant transverse tooth geometry for the helical mesh. The operating conditions where balance beam motion is impending are plotted as a line in figure 11. For small helix angles, the friction forces are very significant compared to the thrust forces, and a large torque imbalance must exist to create motion of the balance beam. The NASA Lewis split torque test gearbox as designed has a $6^{\circ}$ helix angle. The results of the static analysis indicates that the helix angle should be increased to overcome friction and ensure good load sharing. Of course, one must keep in mind that the results shown depend on the assumed coefficient of friction, which is difficult to estimate. Also, changing the helix angle may 
change the strength of the coupling of the axial and torsional vibration modes and therefore the dynamic load sharing.

The gearbox was also evaluated by dynamic analysis. The analytical model is shown in figure 12. Along with the inertia and stiffness elements shown in the figure, the model also includes a damping element parallel to each stiffness element, an input inertia, and an output inertia. The equations of motion were derived by the Lagrangian method. Gear mesh stiffnesses were modeled as time varying to account for both the number of teeth in contact and the varying stiffness of each tooth pair as the gears rotate. Individual tooth pair stiffnesses were calculated using the method of Cornel (ref. 10). The accumulative pitch error of the gears were assumed to have a sine wave shape and were included in the gear mesh model. The simulated loaded static transmission errors were a source of excitation for the system. Bearing supports were modeled with complex stiffnesses with no damping. It was assumed that shafts moved in pure translation and that Coulomb friction forces were negligible. The equations of motion were first made nondimensional using characteristic parameters, then solved using a fifth/sixth order Runge-Kutta method. The characteristic time was chosen to be the design speed of the pinion, and therefore one dimensionless time represents one radian of rotation of the pinion. A computer code based on this analytical model produces results typical of parametrically excited systems with high frequency characteristics restrained by a low frequency envelope (ref. 11).

An analysis was done for a simulated start-up from rest. The externally applied input and output torques are shown in figure 13. As the torques are applied, the stiffness elements deflect. Also, because the opposing torques are not balanced, the loading simulates acceleration from rest or constant velocity. Although the loading to full torque is much more sudden than would occur physically, full torque in $0.45 \mathrm{sec}$, this sudden loading was used to save computation time. Some of the transient motions in the solution are due to this sudden loading of the system.

The simulated rotational motion of the output inertia in dimensionless coordinates is shown in figure 14. The dimensionless coordinates are physical coordinates normalized using characteristic parameters inherent to the gearbox. The output inertia accelerates from rest and has reached a velocity of approximately $12 \mathrm{rpm}$ in $1.5 \mathrm{sec}$. The rotational motion plots of the other inertias, not shown, have similar shapes. Because the rigid body mode is a part of the simulated motion, torsional vibrations are difficult to observe in such a plot. Therefore, the rigid body mode was eliminated from the results by referencing all torsional displacements to the position of the input inertia.

The dynamic angular motions of the pinion and bull gear with respect to the input inertia are shown in figure 15 along with the static solution. Also, their lateral motions are plotted as shaft orbits in figure 16. Note that the pinion has a large torsional vibration during start-up. The frequency of torsional vibration for the pinion is approximately $37.5 \mathrm{~Hz}$, which is the rotational frequency of the compound shafts. The bull gear also has a small torsional vibration at one half of the compound shaft frequency of $18.7 \mathrm{~Hz}$. The accumulative pitch errors of the gears of the compound shafts are the excitation source of these torsional vibrations. The bull gear is overshooting the expected steady state mean torsional displacement in response to the sudden ramp loading but the motion is stable. The shaft orbits shown in figure 16 are typical of all lateral motions in that they are bound and stable. A study of all the motions indicate that the transient response to the sudden loading is significant and that a drive system start-up from rest has been reasonably simulated using ramp shaped forcing functions that accelerate the system. 
An analysis using a step function to start the system at time zero produced very large transient motions not representative of realistic physical motions.

The analytical results were studied to evaluate the load sharing characteristics of the system. The dynamic torques in the four shafts of the system along with torques for a static solution are shown in figure 17. Note that the dynamic means follows the static solutions with some torsional vibrations and overshoot at the end of the ramp loading for dimensionless time 400 . The plot of the torques of the compound shafts (fig. 17(c)) show excellent load sharing during start-up in spite of a torsional vibration response to accumulative pitch errors. To further evaluate the load balancing mechanism of this design, a second analysis was completed that was identical to the first except the initial axial positions of the two compound shafts were offset from their nominal positions. Therefore, the balance beam position was not zero at time equal to zero. The rotation of the balance beam for the two cases are shown in figure 18. The frequency of rotation is approximately $16.5 \mathrm{~Hz}$. This frequency is not directly related to any shaft rotational speed. Note that the motion for the case of an offset initial condition (18(b)) quickly approaches that of the nominal case. The magnitude of the balance beam rotations is very small. The load sharing during start-up for the offset condition case is shown in figure 19. The load sharing shown is typical of the entire solution. The dynamic load sharing is satisfactory in that the torques are within about 5 percent of each other. It is interesting that a small torque ripple at the input shaft frequency of $147.5 \mathrm{~Hz}$ appears in only one of the two compound shaft torques. The load sharing for the case of nominal positions for the compound shafts was even better than that shown in figure 19.

The dynamic response of the system to a start-up condition showed satisfactory load sharing. The accumulative pitch errors of the gears excited significant torsional vibration of the pinion and smaller but noticeable vibrations in the other shafts. The balancing mechanism responds quickly to an initial offset condition so long as friction is negligible. Although this analysis predicts good load sharing, the recently completed static analysis with friction presented earlier in this paper indicates that frictional forces are significant. These frictional forces were assumed negligible in the dynamic analysis presented here. A dynamic analysis of any split torque design that relies on axial motions to balance the torque split should include the frictional forces that oppose axial motion to best evaluate the effectiveness of the design. While the introduction of friction forces to the model may change the effectiveness of the balance mechanism, the effect of friction could be minimized by increasing the helix angle of the pinion. Also, the basic vibrational characteristics of any system are a property only of the masses, stiffnesses, damping, and geometry of the design and not of the forces. Including frictional forces in the model may produce slightly different responses for a given input, but the frictional forces will not change the significant vibration modes or frequencies of the system that were presented here.

\section{SUMMARY OF RESULTS}

Two designs that use split torque concepts have been studied to evaluate three different load sharing concepts. The Sikorsky Aircraft Split Path Transmission design developed under the Advanced Rotorcraft Transmission Program was studied. Two load sharing concepts for this design were evaluated; (1) a torsionally compliant device, and (2) precise indexing and assembly when using a conventional, torsionally stiff shaft. This design was studied experimentally. The NASA Lewis Split Torque Gearbox was studied analytically to evaluate a self adjusting, thrust balancing mechanism for load sharing. 
The following specific results were obtained from a study of the Sikorsky Aircraft design.

1. Although a split torque gearbox is geometrically symmetric, the loads and motions of the two power paths are not.

2. Precise indexing, tolerancing, and assembly of a gearbox can be used with a torsionally stiff shaft to produce an acceptable torque split.

3. An elastomeric torque splitting device that has a large compliance and damping produced even better load sharing and lower levels of dynamic transmission error and noise.

4. While the elastomeric torque splitter has attractive characteristics, in its present configuration it is not capable over the full range of operating temperatures for a fielded system. However, an alternative robust design that has a large torsional compliance and damping for load sharing may be possible.

The following specific results were obtained from a study of the NASA Lewis design.

1. For small helix angles, the friction forces that act to resist motion of the thrust balance mechanism are significant. The static analysis suggests to increase the helix angle, but the effect on the system's dynamics must also be considered.

2. A dynamic analysis of the start-up of a drive system from rest was reasonably simulated using ramp shaped forcing functions that accelerated the system.

3. Assuming negligible friction, the dynamic analysis predicts that a split torque gearbox with a thrust balance mechanism for load sharing exhibits excellent load sharing during start-up. The balance beam mechanism responds quickly to an initial offset condition.

4. Dynamic analysis also predicts that the the accumulative pitch errors of the gears are a significant source of torsional vibrations of the system.

\section{REFERENCES}

1. White G., 1974, "New Family of High-Ratio Reduction Gear with Multiple Drive Paths," Proc. Instn. Engrs., Vol. 188, IMech, pp. 281-288.

2. White G., 1982, "Design Study of Split-Torque Helicopter Transmissions," NASA Contractor Final Report, Contract NAS3-22528.

3. White, G., 1983, "Design of A 375 KW Helicopter Transmission with Split-Torque Epicyclic and Bevel Drive Stages," Proc. Instn. Mech. Engrs., Part C, Vol. 197, pp. 213-224.

4. Coy, J., 1983, "Geared Power Transmission Technology, Advanced Power Transmission Technology," George K. Fisher, ed., NASA CP-2210, pp. 49-77.

5. Coy, J. and Bill, R., 1988, "Advanced Transmission Studies," NASA Technical Memorandum 100867. 
6. Kish, J., 1991, "Advanced Rotorcraft Transmission (ART)-Program Status," AIAA paper 91-1909, presented at AIAA/SAE/ASME/ASEE 27th Joint Propulsion Conference, Sacramento, Califonia.

7. Kish, J., 1990, "Advanced Rotorcraft Transmission (ART) Program Review," presented at the Rotary Wing Propulsion Specialists' Meeting Sponsored by the Hampton Roads Chapter Southeast Region American Helicopter Society, AHS Preprint No. 5, Williamsburg, Virginia.

8. Krantz, T. and Kish, J., 1992 "Advanced Rotorcraft Transmission (ART) Program Summary," NASA Technical Memorandum 105665.

9. Hamrock, B., 1991, "Fundamentals of Fluid Film Lubrication," NASA Reference Publication 1255 .

10. Cornel, R.W., 1981, "Compliance and Stress Sensitivity of Spur Gear Teeth," Journal of Mechanical Design, 103, (2), pp. 447-459.

11. Rashidi, M. and Krantz, T., 1992, "Dynamics of a Split Torque Helicopter Transmission," NASA Technical Memorandum 105681. 
TABLE I.-RESULTS OF STATIC ANALYSIS

(Bearing Forces at Full Design Load)

\begin{tabular}{|c|c|c|c|}
\hline $\begin{array}{c}\text { Bearing } \\
\text { location }\end{array}$ & $\frac{\text { load }}{\mathrm{K} \cdot \mathrm{N}}$ & $\left(\frac{\text { load }}{\mathrm{lb}}\right)$ & $\frac{\text { load direction }}{\text { degrees }}$ \\
\hline 1 & 3.57 & $(800)$ & 24 \\
2 & 4.57 & $(1030)$ & 17 \\
3 & 15.6 & $(3520)$ & 137 \\
4 & 6.05 & $(1360)$ & 176 \\
5 & 18.0 & $(4040)$ & 174 \\
6 & 14.3 & $(3210)$ & 164 \\
7 & 29.5 & $(6640)$ & 335 \\
8 & 16.2 & $(3650)$ & 335 \\
\hline
\end{tabular}

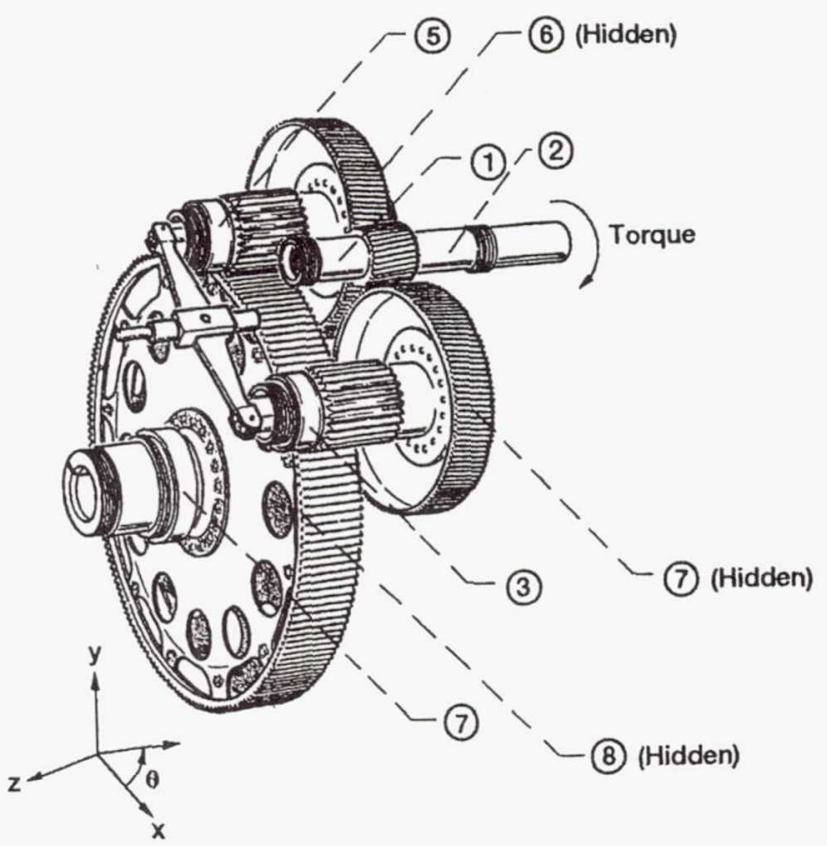


TABLE II. -BULL GEAR ROLLER BEARING STIFFNESS MATRIX

\begin{tabular}{|l|l|}
\hline & $\frac{\text { Stiffness, } \mathrm{K}}{\left(\frac{\mathrm{kN} \times 10^{6}}{\mathrm{~m}}\right)}$ \\
\hline $\mathrm{X}=$ direction of bearing force & {$\left[\begin{array}{ll}1.99 & 1.21 \\
1.21 & 1.67\end{array}\right]$} \\
\hline $\mathrm{X}=$ direction of gear mesh force & {$\left[\begin{array}{rr}2.87 & -0.65 \\
-0.65 & 0.80\end{array}\right]$} \\
\hline Notation $\mathrm{K}=\left[\begin{array}{ll}\mathrm{K}_{\mathrm{xx}} & \mathrm{K}_{\mathrm{xy}} \\
\mathrm{K}_{\mathrm{yx}} & \mathrm{K}_{\mathrm{yy}}\end{array}\right]$ \\
\hline
\end{tabular}

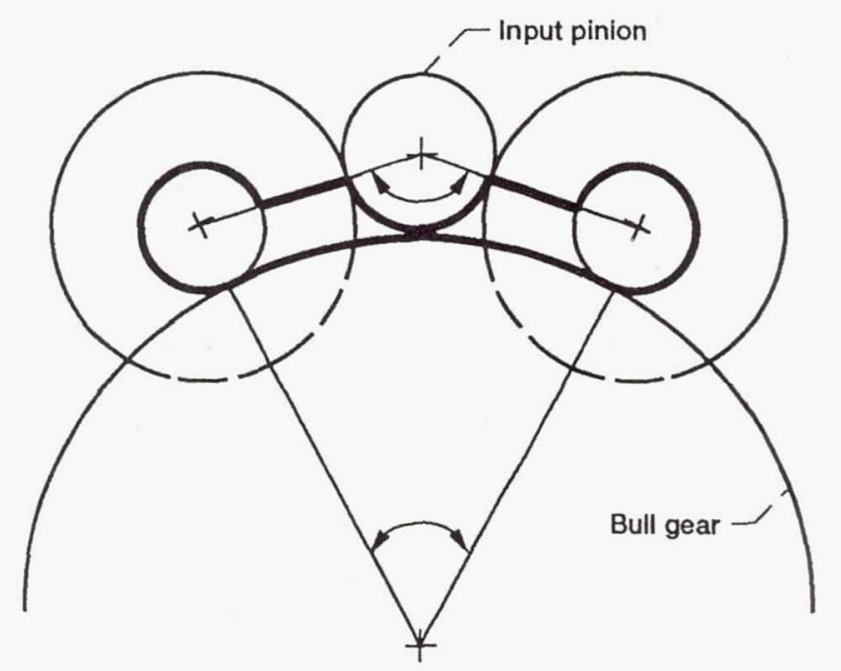

Figure 1.-Split-torque geometry. 


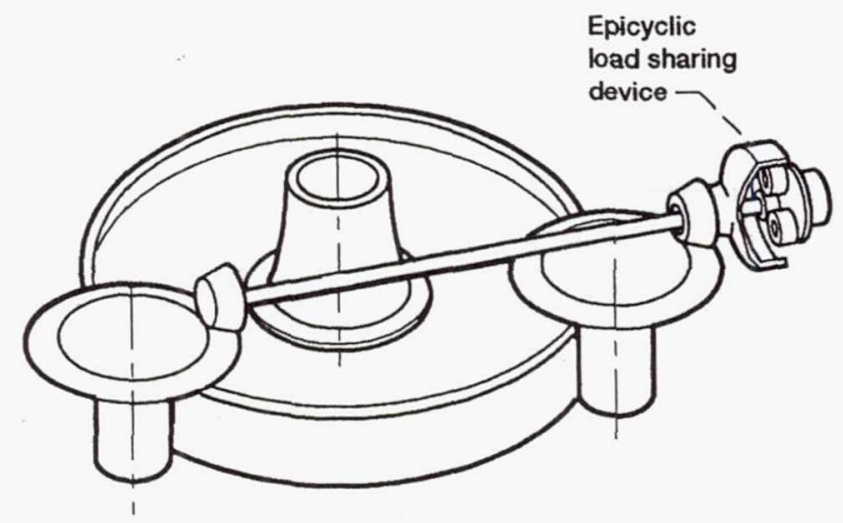

Figure 2-Split-torque design with epicyclic load sharing device.

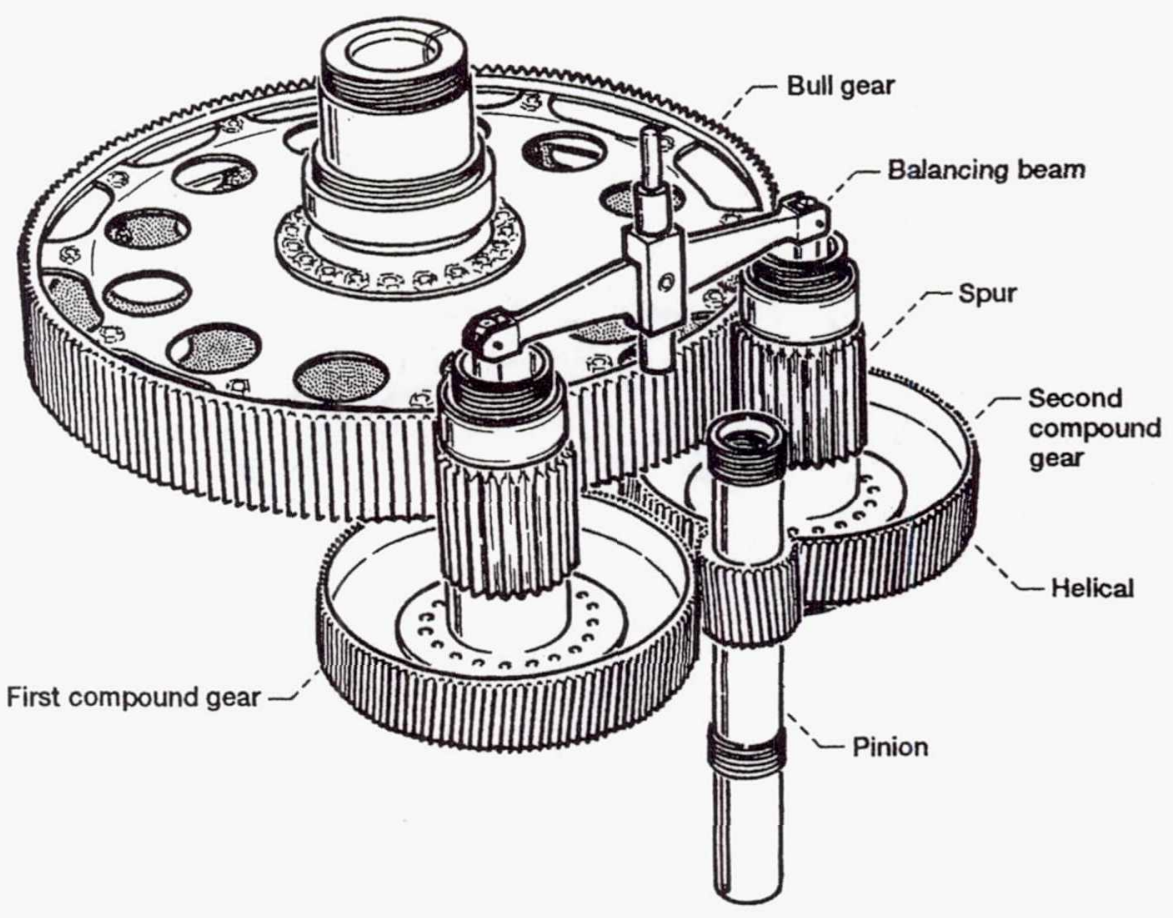

Figure 3.-Pictorial view of a split-torque helicopter transmission with two power paths. 


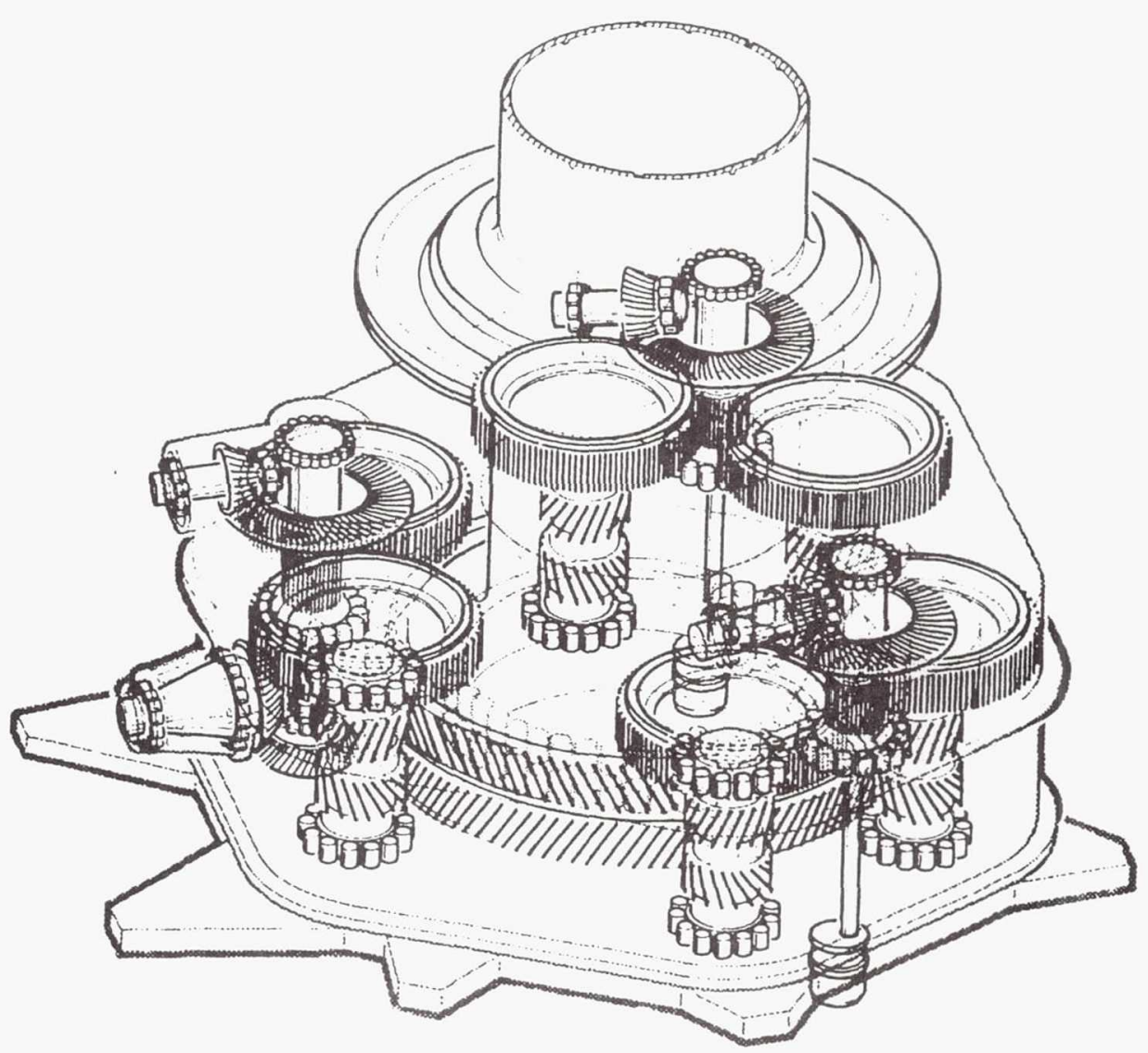

(a) Isometric view.

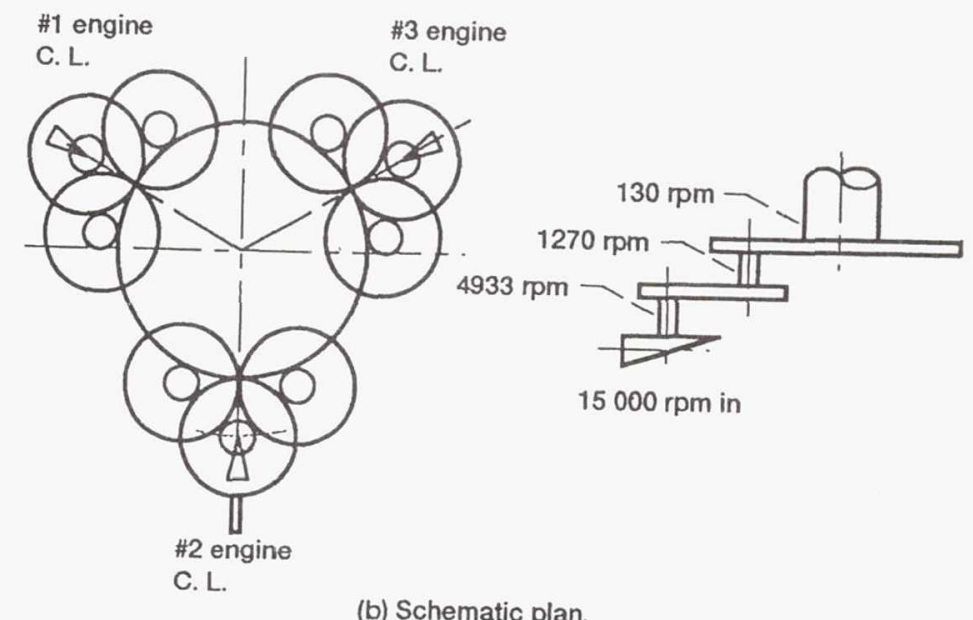

Figure 4.-Advanced cargo aircraft split path transmission. 


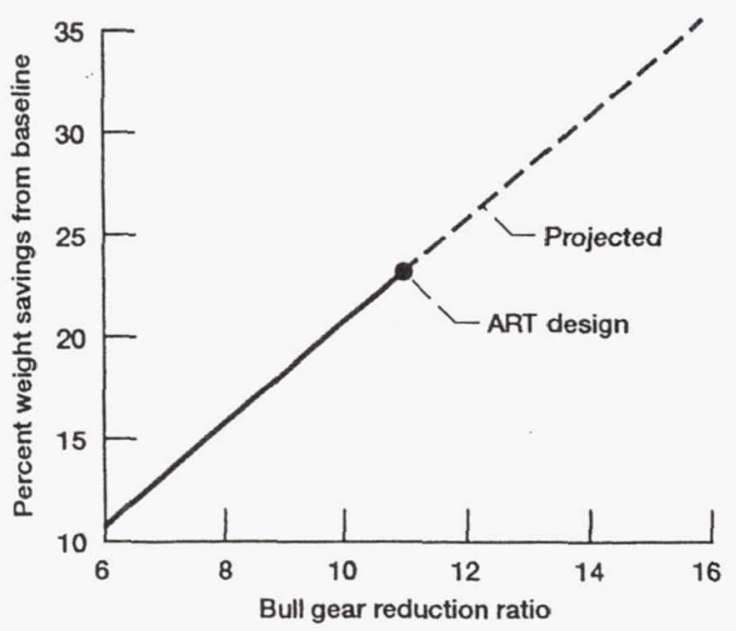

Figure 5.-Effect of bull gear reduction ratio on transmission weight.

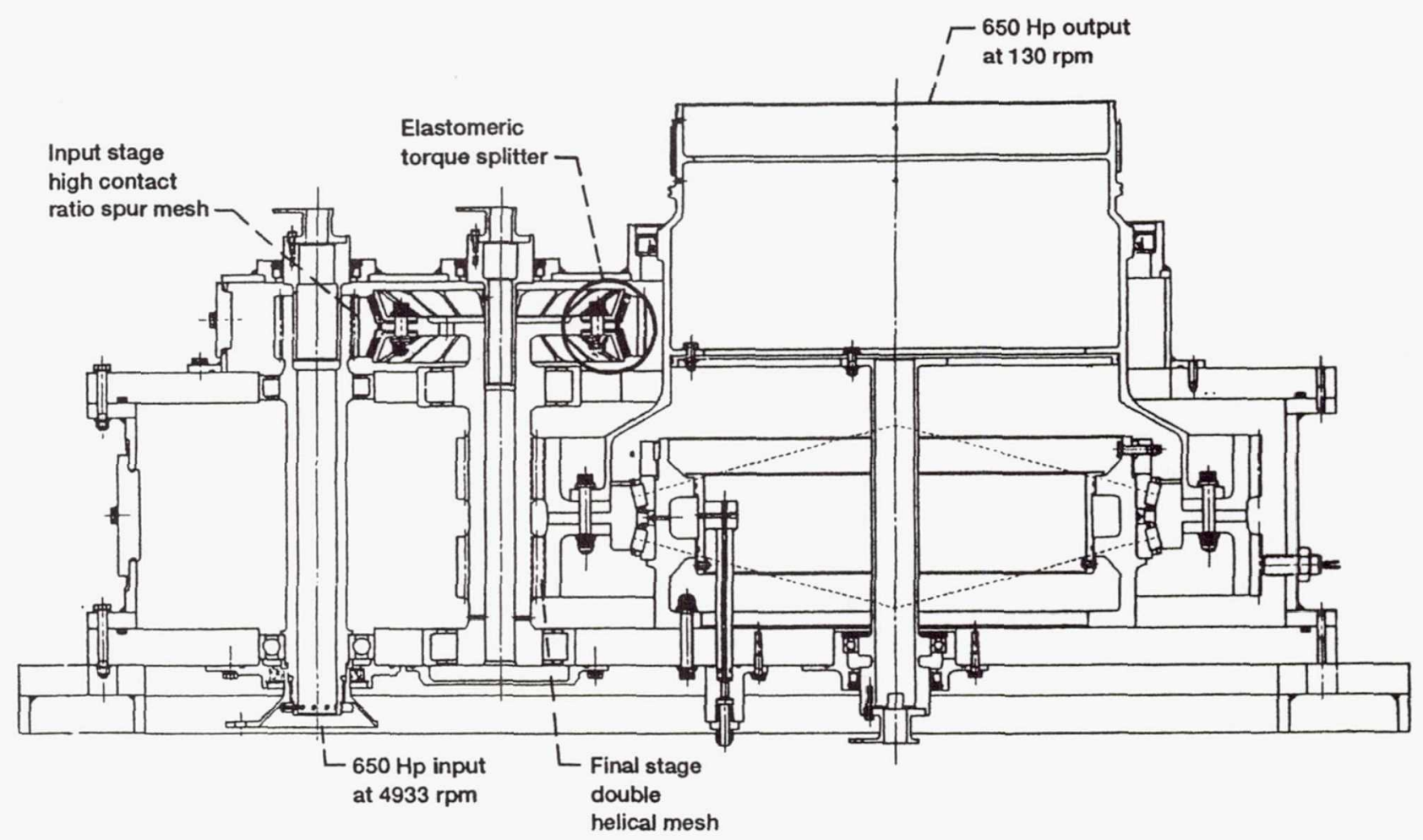

Figure 6.-ART 1/2 scale split-torque gearbox. 


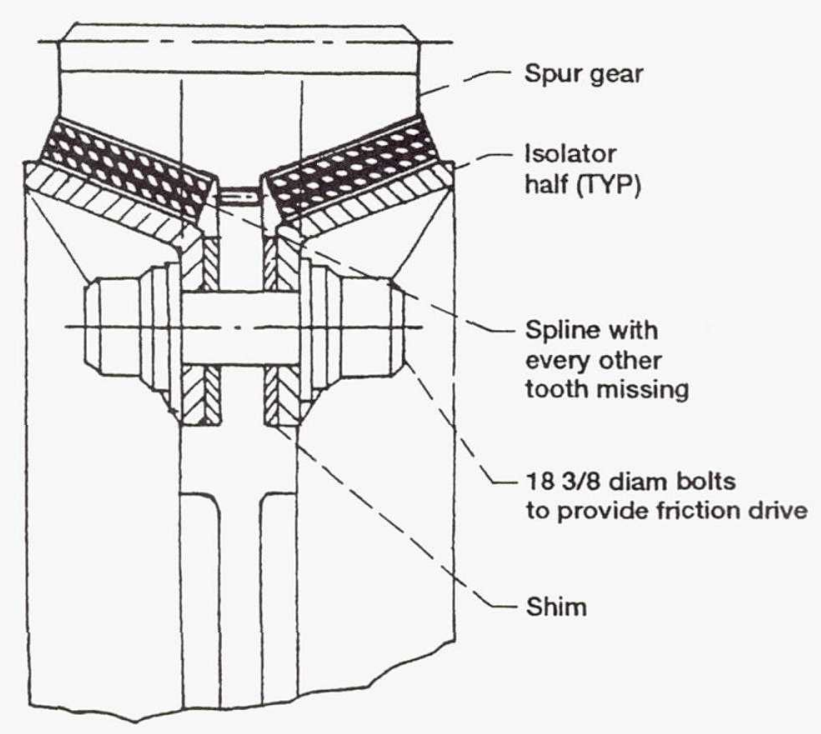

(a) Cross section.

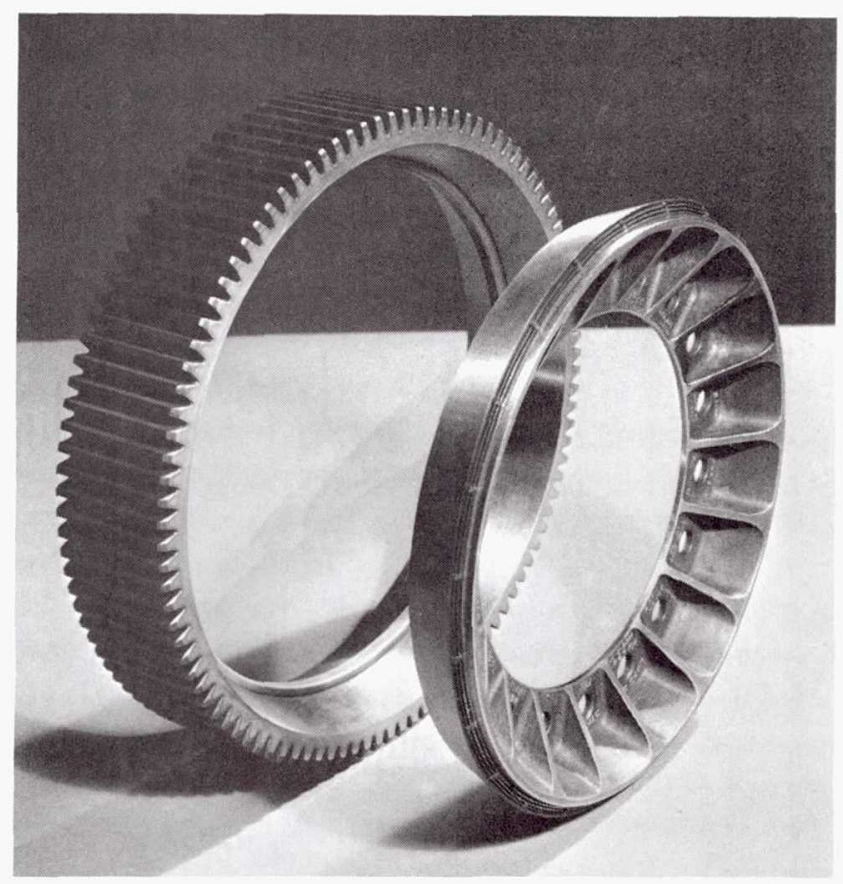

(b) Spur gear and isolator component.

Figure 7.-Elastomeric, torsionally compliant load sharing device. 


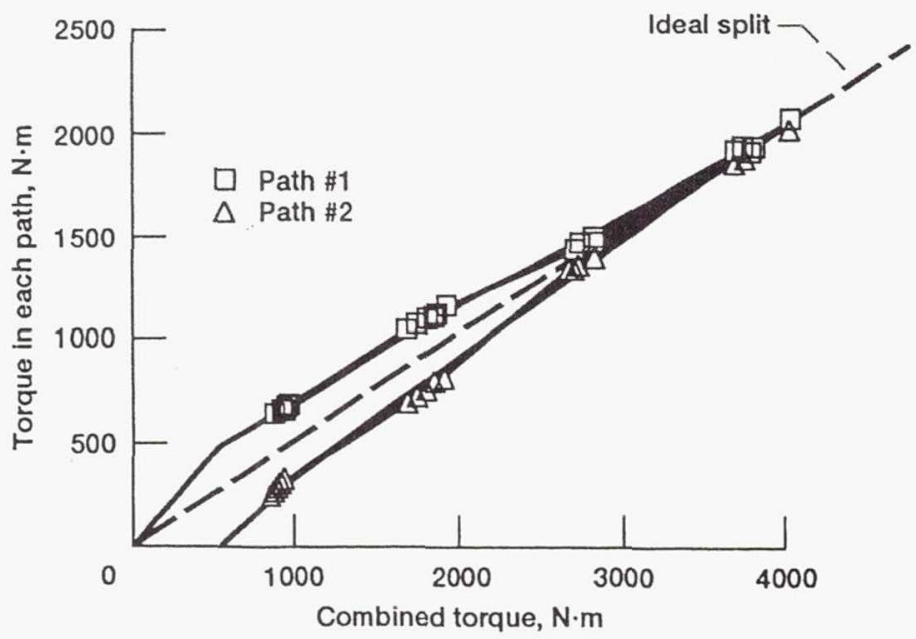

Figure 8.-Measured torque split with elastomeric isolators.

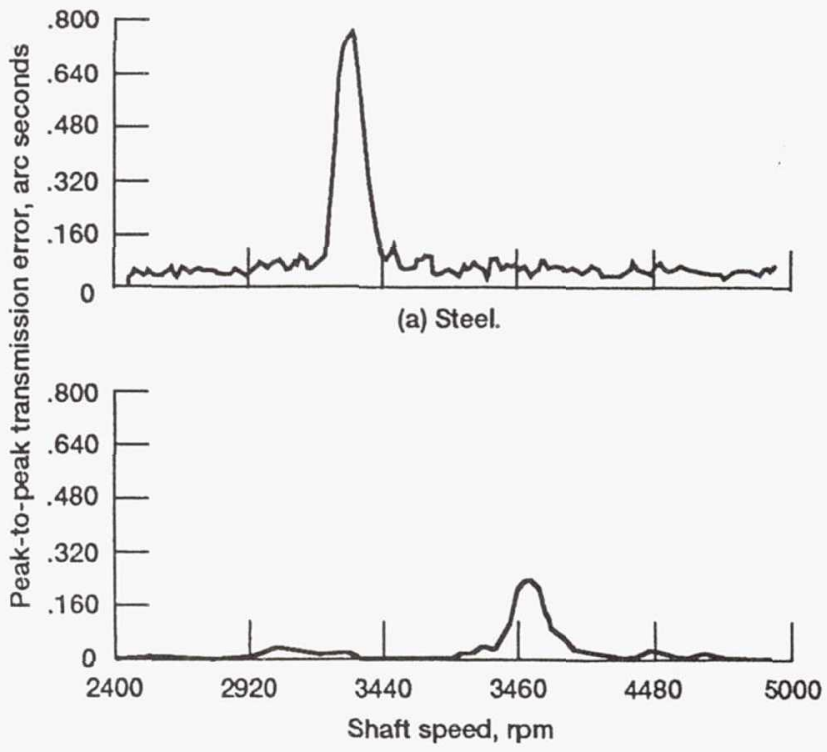

(b) Elastomer.

Figure 9.--Transmission error vs rpm for upper helical mesh with and without elastomeric load sharing device installed. 


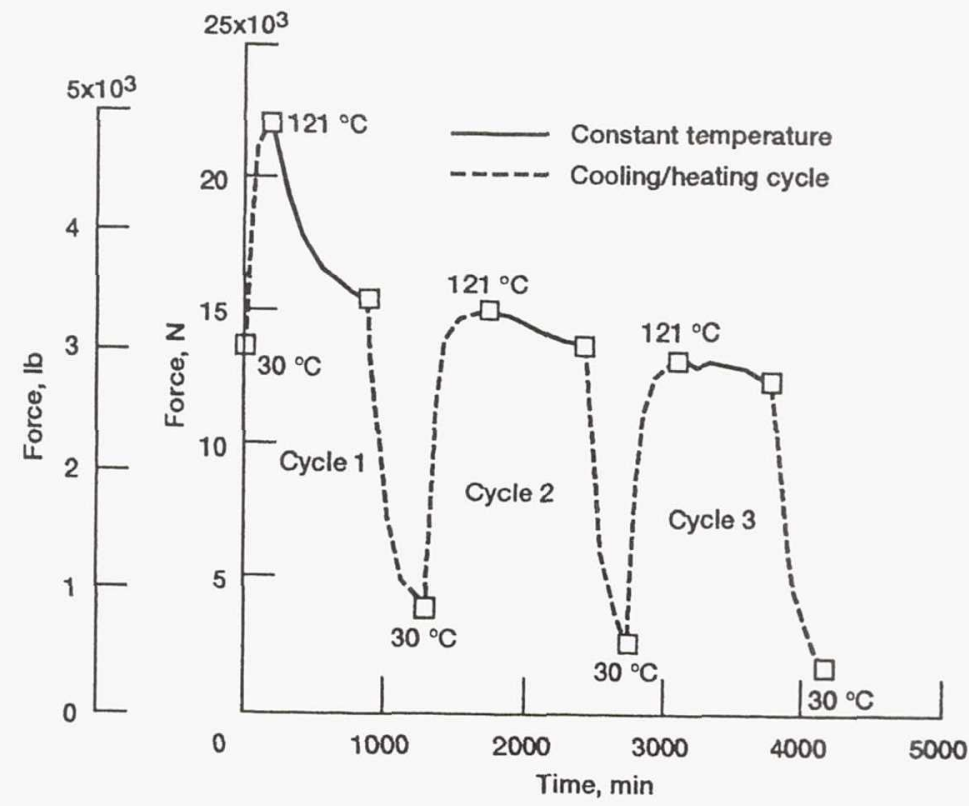

Figure 10.-Measured laminate compressive load vs time with temperature cycling and constant deflection.

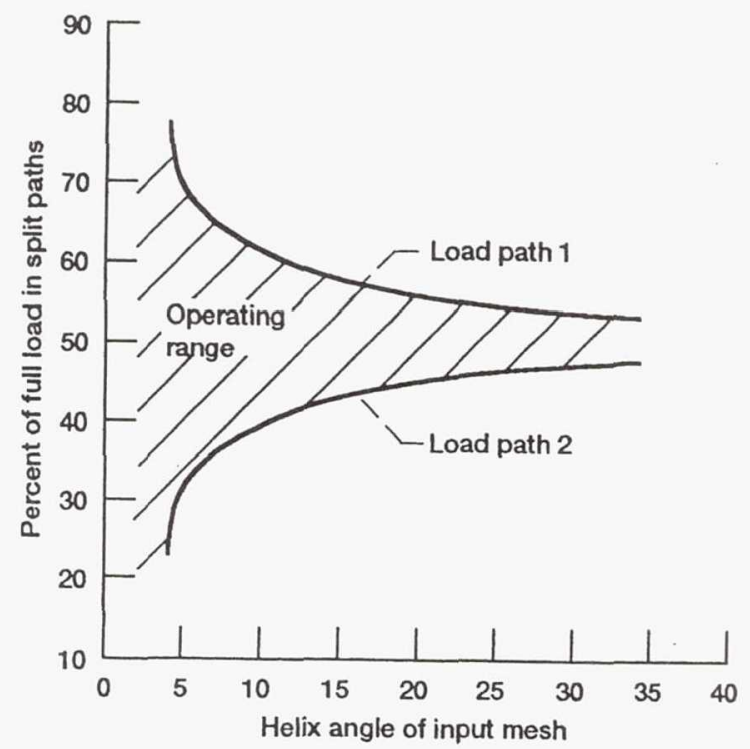

Figure 11.-Load condition to create balance beam motion (for friction coefficient $=0.005$ ). 


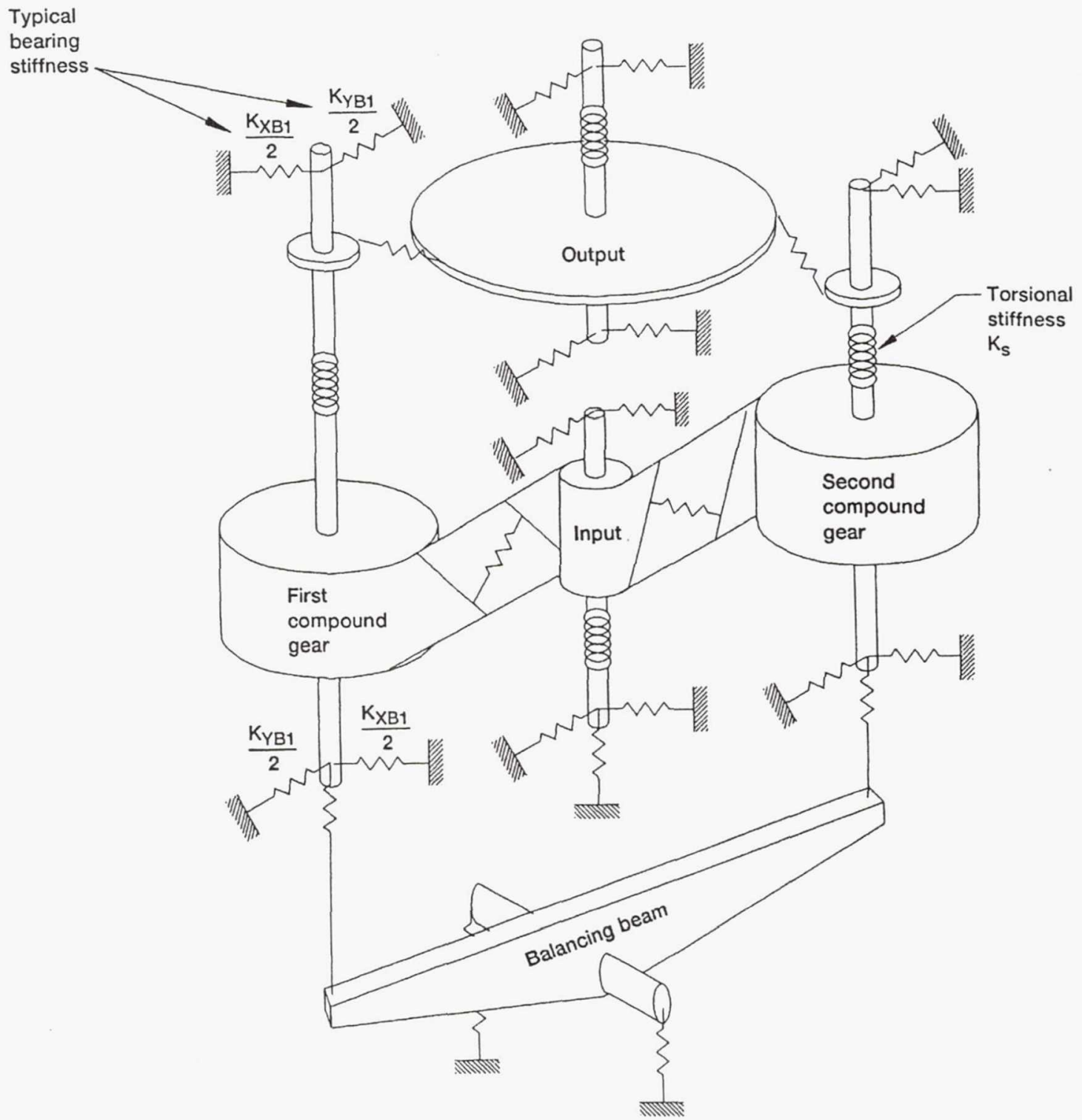

Figure 12.-Split-torque model. Note: not shown, damping elements, input inertia, output inertia. 


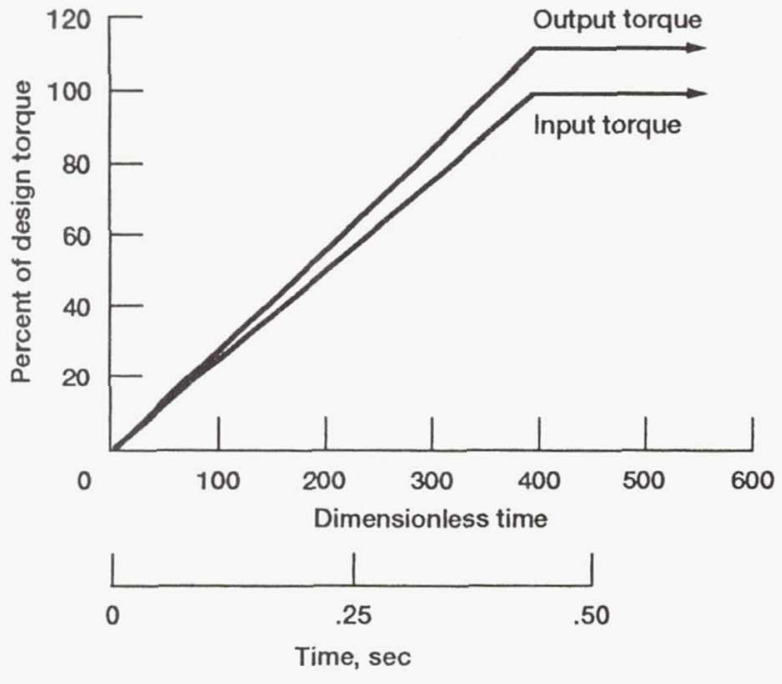

Figure 13.-Externally applied loads.

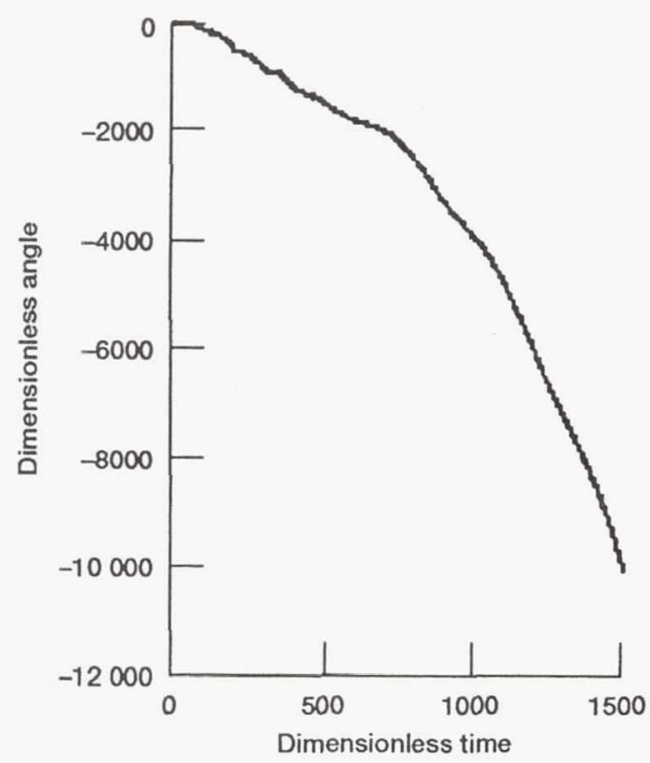

Figure 14.-Motion of output inertia during start up.

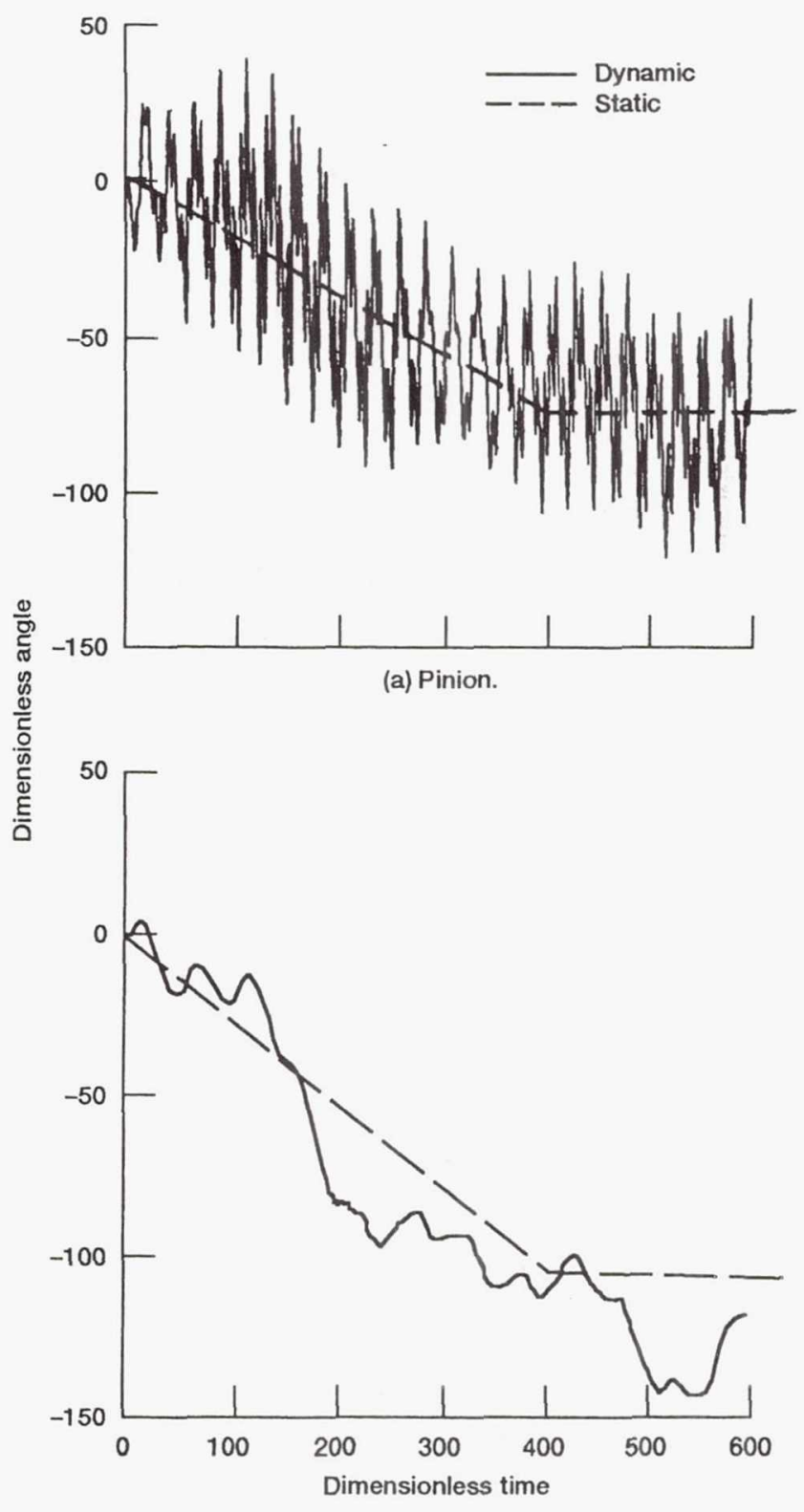

(b) Bull gear.

Figure 15.-Angular motions relative to input inertia. 


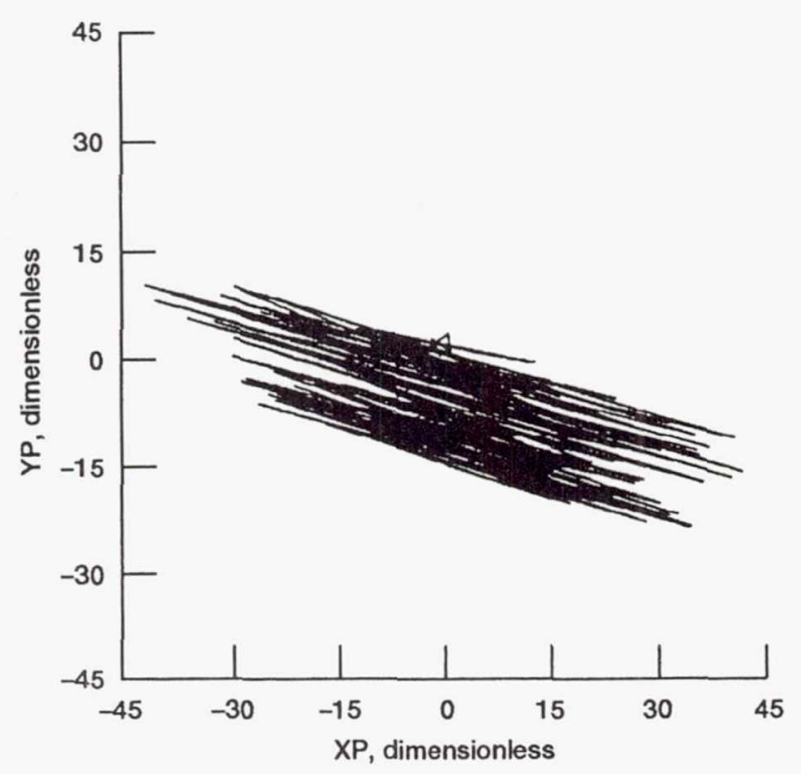

(a) Pinion shaft orbit during start up.

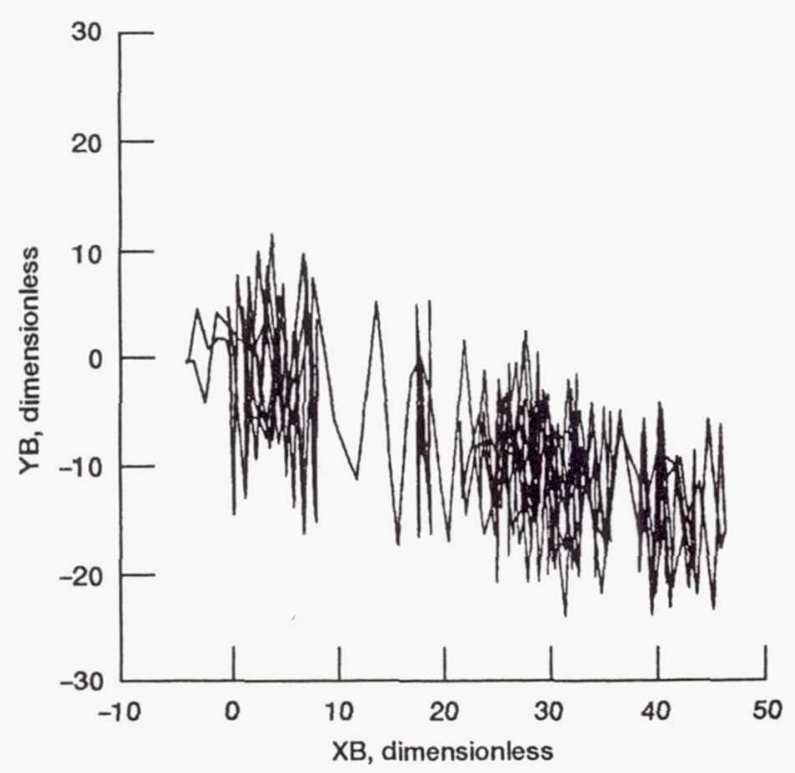

(b) Bull gear shaft orbit during start up.

Figure 16.-Lateral motions during start up.
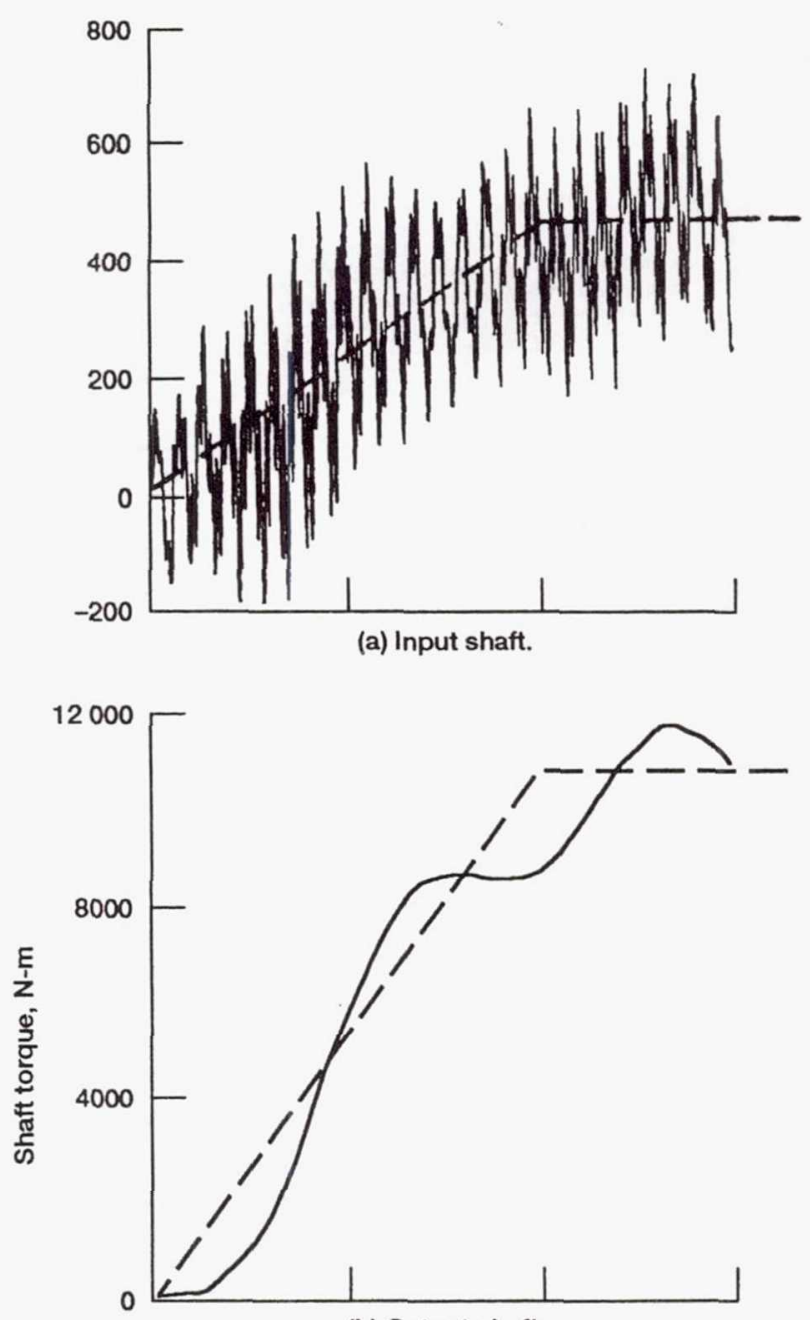

(b) Output shaft.

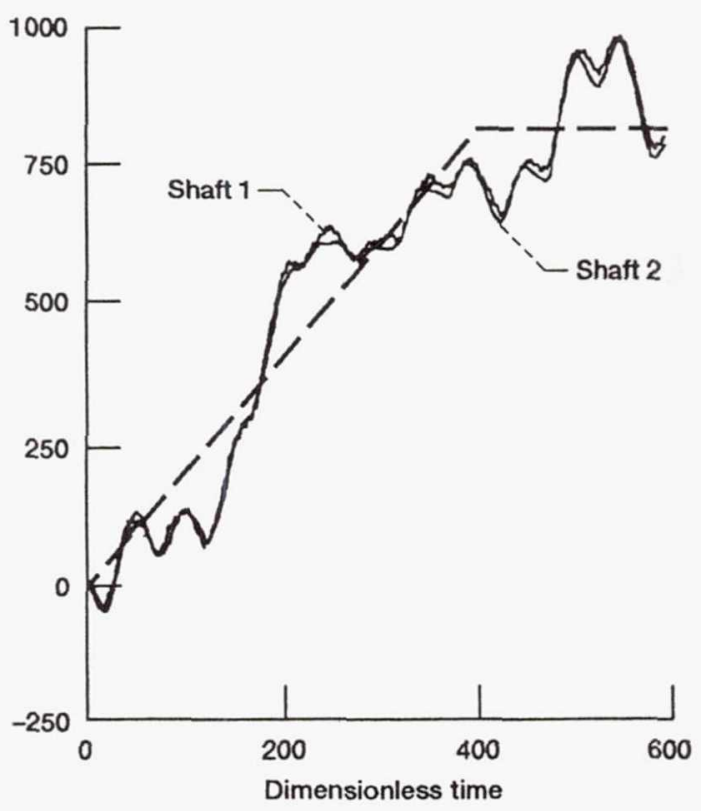

(c) Compound shafts.

Figure 17.-Shaft torques during start up. 


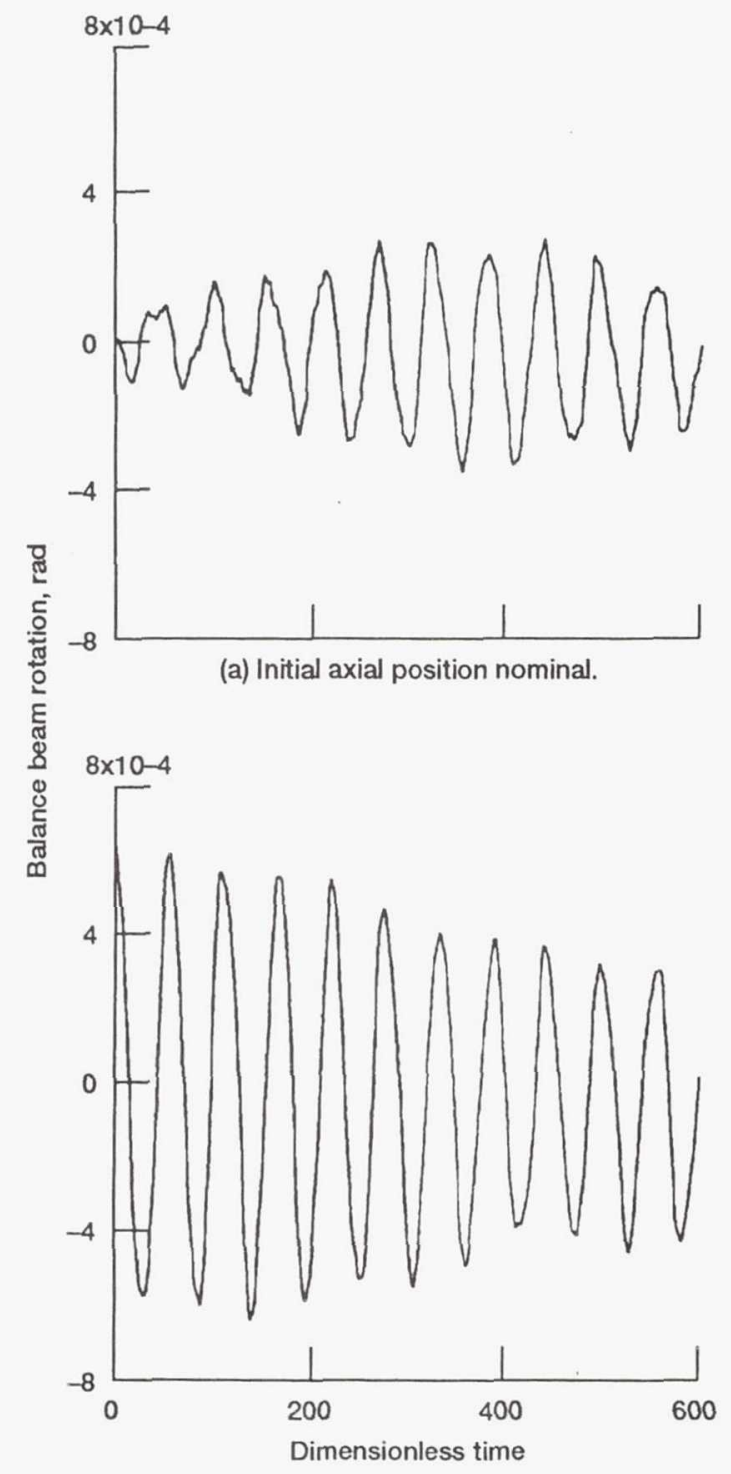

(b) Initial axial position offset.

Figure 18.-Balance beam rotation during start up.

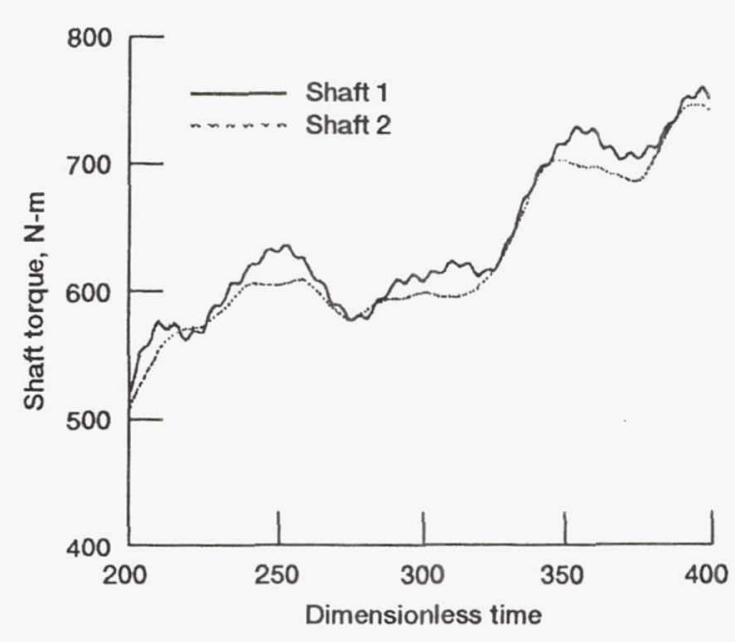

Figure 19.-Load sharing with initial position offset. 
Public reporting burden for this collection of information is estimated to average 1 hour per response, including the time for reviewing instructions, searching existing data sources, gathering and maintaining the data needed, and completing and reviewing the collection of information. Send comments regarding this burden estimate or any other aspect of this collection of information, including suggestions for reducing this burden, to Washington Headquarters Services, Directorate for information Operations and Reports, 1215 Jefferson Davis Highway, Suite 1204, Arlington, VA 22202-4302, and to the Office of Management and Budget, Paperwork Reduction Project (0704-0188), Washington, DC 20503.

\begin{tabular}{|l|c|c|} 
1. AGENCY USE ONLY (Leave blank) & $\begin{array}{r}\text { 2. REPORT DATE } \\
\text { October } 1992\end{array}$ & $\begin{array}{r}\text { 3. REPORT TYPE AND DATES COVERED } \\
\text { Technical Memorandum }\end{array}$ \\
\hline
\end{tabular}

\section{TITLE AND SUBTITLE}

Split Torque Transmission Load Sharing

6. AUTHOR(S)

T.L. Krantz, M. Rashidi, and J.G. Kish
5. FUNDING NUMBERS

WU-505-63-36

1L162211A47A

8. PERFORMING ORGANIZATION REPORT NUMBER

E-7350

Propulsion Directorate

U.S. Army Aviation Systems Command

Cleveland, Ohio 44135-3191

9. SPONSORING/MONITORING AGENCY NAMES(S) AND ADDRESS(ES)

National Aeronautics and Space Administration

Washington, D.C. 20546-0001

and

U.S. Army Aviation Systems Command

St. Louis, Mo. 63120-1798

10. SPONSORING/MONITORING AGENCY REPORT NUMBER

NASA TM-105884

AVSCOM-TR-92-C-030

11. SUPPLEMENTARY NOTES

Prepared for the "Gearbox Configurations of the 90's" sponsored by the Institute of Mechanical Engineers Solihull, West Midlands, United Kingdom, October 28, 1992. T.L. Krantz, Propulsion Directorate, U.S. Army Aviation Systems Command. M. Rashidi, Cleveland State University Mechanical Engineering Department, Cleveland, Ohio 44115. J.G. Kish, Sikorsky Aircraft, Stratford, Connecticut 06601-1381. Responsible person, T.L. Krantz, (216) 433-3580.

12a. DISTRIBUTION/AVAILABILITY STATEMENT

12b. DISTRIBUTION CODE

Unclassified - Unlimited

Subject Category 37

13. ABSTRACT (Maximum 200 words)

Split torque transmissions are attractive alternatives to conventional planetary designs for helicopter transmissions. The split torque designs can offer lighter weight and fewer parts but have not been used extensively for lack of experience, especially with obtaining proper load sharing. Two split torque designs that use different load sharing methods have been studied. Precise indexing and alignment of the geartrain to produce acceptable load sharing has been demonstrated. An elastomeric torque splitter that has large torsional compliance and damping produces even better load sharing while reducing dynamic transmission error and noise. However, the elastomeric torque splitter as now configured is not capable over the full range of operating conditions of a fielded system. A thrust balancing load sharing device was evaluated. Friction forces that oppose the motion of the balance mechanism are significant. A static analysis suggests to increase the helix angle of the input pinion of the thrust balancing design. Also, dynamic analysis of this design predicts good load sharing and a significant torsional response to accumulative pitch errors of the gears.

\begin{tabular}{|c|c|c|}
\hline $\begin{array}{c}\text { 14. SUBJECT TERMS } \\
\text { Torque; Planetary; Transmissions; Load sharing; Gear noise }\end{array}$ \\
$\begin{array}{c}\text { 17. SECURITY CLASSIFICATION } \\
\begin{array}{c}\text { OF REPORT } \\
\text { Unclassified }\end{array}\end{array} \begin{array}{c}\text { 18. SECURITY CLASSIFICATION } \\
\text { OF THIS PAGE } \\
\text { Unclassified }\end{array}$ & $\begin{array}{c}\text { 19. SECURITY CLASSIFICATION } \\
\text { OF ABSTRACT } \\
\text { Unclassified }\end{array}$ \\
\hline
\end{tabular}


National Aeronautics and Space Administration

Lewis Research Center

Cleveland, Ohio 44135

Official Business

Penalty for Private Use $\$ 300$
Postage and Fees Paid National Aeronautics and Space Administration NASA 451 